Article

\title{
Obesity-Related Metabolic Risk in Sedentary Hispanic Adolescent Girls with Normal BMI
}

\author{
Gert-Jan van der Heijden ${ }^{1, *(1)}$, Zhiyue J. Wang ${ }^{2}$ (D), Zili D. Chu ${ }^{3,4}$, Morey Haymond ${ }^{1}$, \\ Pieter J. J. Sauer ${ }^{5}$ and Agneta L. Sunehag ${ }^{1}$ \\ 1 Department of Pediatrics, Baylor College of Medicine, Houston, TX 77030, USA; \\ mhaymond@bcm.edu (M.H.); asunehag@gmail.com (A.L.S.) \\ 2 Department of Radiology, University of Texas Southwestern Medical Center, Dallas, TX 75390, USA; \\ JERRY.WANG@childrens.com \\ 3 Department of Radiology, Baylor College of Medicine, Houston, TX 77030, USA; zchu@bcm.edu \\ 4 Department of Pediatric Radiology, Texas Children's Hospital, Houston, TX 77030, USA \\ 5 Department of Pediatrics, Beatrix Children's Hospital, University Medical Center Groningen, \\ University of Groningen, Groningen 9713 GZ, The Netherlands; saupie46@gmail.com \\ * Correspondence: gertjanvanderheijden@gmail.com; Tel.: +35-191-0796128
}

Received: 23 April 2018; Accepted: 11 June 2018; Published: 15 June 2018

\begin{abstract}
Hispanic adolescent girls with normal BMI frequently have high body fat \%. Without knowledge of body fat content and distribution, their risk for metabolic complications is unknown. We measured metabolic risk indicators and abdominal fat distribution in post-pubertal Hispanic adolescent girls with Normal BMI (N-BMI: BMI < 85th percentile) and compared these indicators between girls with Normal BMI and High Fat content (N-BMI-HF: body fat $\geq 27 \% ; n=15$ ) and Normal BMI and Normal Fat content (N-BMI-NF: body fat $<27 \% ; n=8)$. Plasma concentrations of glucose, insulin, adiponectin, leptin and Hs-CRP were determined. Insulin resistance was calculated using an oral glucose tolerance test. Body fat \% was measured by DXA and subcutaneous, visceral and hepatic fat by MRI/MRS. The N-BMI-HF girls had increased abdominal and hepatic fat content and increased insulin resistance, plasma leptin and Hs-CRP concentrations $(p<0.05)$ as compared to their N-BMI-NF counterparts. In N-BMI girls, insulin resistance, plasma insulin and leptin correlated with BMI and body fat $\%(p<0.05)$. This research confirms the necessity of the development of BMI and body fat \% cut-off criteria per sex, age and racial/ethnic group based on metabolic risk factors to optimize the effectiveness of metabolic risk screening procedures.
\end{abstract}

Keywords: BMI; body fat; abdominal fat; Hispanic; insulin resistance

\section{Introduction}

Obesity in adolescence is related to well-known metabolic derangements such as insulin resistance, high blood pressure, dyslipidemia, type 2 diabetes and the development of cardiovascular disease in adulthood [1]. The Body Mass Index (BMI) (weight in $\mathrm{kg} /(\text { height in } \mathrm{m})^{2}$ ) [2] is used to distinguish between individuals with a normal and high risk of developing obesity-related complications. BMI, however, is not an optimal marker of leanness/obesity [3], and adolescents with normal BMI can have high fat mass [3-5]. Fat content [3-7] and the specific pattern of high visceral and low subcutaneous abdominal fat distribution, ectopic fat deposition and adipose tissue dysfunction contribute to obesity-related complications [8-13]. Low grade chronic whole body inflammation as a result of oxidative and endoplasmic reticulum stress related to nutrient excess is related to cardiovascular disease (CVD) in adults and is elevated in obese adolescents [14-16]. In addition, it is proposed that adipocyte dysfunction is related to obesity-related morbidity $[14,17,18]$. Leptin resistance is related to CVD risk [14], whereas a high adiponectin concentration 
is purported to have a protective effect on insulin sensitivity partly attributed to its anti-inflammatory function [14,18]. It is currently not known if whole body inflammation and adipocyte dysfunction are present in adolescents with normal BMI.

At present, the potential discrepancy between BMI and obesity-related metabolic risk is recognized in specific racial/ethnic groups, predominately in the Asian population [19-21].

In addition, it has been known that the Hispanic population is at a high risk of obesity and obesity-related illnesses [22-25]. Hispanic adolescent girls have a relatively high body fat percentage in comparison with their white and black counterparts [5,26]. Moreover, in screening procedures for previous studies $[8,16,27]$, we noted that $60 \%$ of sedentary Hispanic adolescent girls with a normal BMI have a high body fat $\%(\geq 27 \%)$ [28]. It is currently not known if a normal BMI in sedentary Hispanic adolescents with a normal or high body fat \% is an indicator of the absence of metabolic risk, especially in girls with a high body fat $\%$.

To address this issue, a wide range of metabolic risk indicators and body fat distributions using state of the art body composition measurements were measured in sedentary normal BMI Hispanic girls.

\section{Materials and Methods}

\subsection{Participants}

After approval of the protocol by the Baylor College of Medicine Institutional Review Board for Human Subject Research and the General Clinical Research Center Advisory Board, adolescents were recruited by local advertisement. Adolescents were screened and enrolled in the study after written assent from the participant and consent from the legal guardian were obtained. Only post-pubertal (Tanner pubertal Stages IV-V, age range 13-17 years) sedentary Hispanic adolescent girls with a normal BMI (<85th percentile/age) were included. BMI cut-off criteria were based on CDC growth charts [2]. Their sedentary behavior was defined as not participating in any school or after-school organized athletic activities and less than $45 \mathrm{~min}$ light to moderate physical activity per week.

All participants had parents and grandparents of Hispanic descent by self-report and reported stable body weight for at least six months. In addition, all participants were in good health as determined by medical history, a physical examination and a standard blood chemistry analysis including blood lipids, liver, as well as kidney function tests, hemoglobin, hematocrit, hemoglobin $\mathrm{A} 1 \mathrm{c}$ and fasting and 2-h post-prandial glucose response. Furthermore, participants were not taking medications, including birth control pills, and had no first-degree relatives with diabetes.

To evaluate the potentially specific effect of high body fat $\%$ on metabolic parameters, the adolescents (all of whom had a normal BMI of $<85$ th percentile/age (N-BMI)) were partitioned by their body fat content: High Fat (HF) girls: body fat $\geq 27 \%$; Normal Fat (NF) girls: body fat $<27 \%$. Body fat \% criteria were based on data from Shypailo et al. [28].

\subsection{Study Design}

Three days prior to the study, each participant received a controlled diet with a fixed macronutrient distribution to exclude the effects of dietary intake on the experimental results (identical in all participants) as previously described $[8,16]$. Participants were admitted to the metabolic research unit at Children's Nutrition Research Center Houston, Texas, the evening before the study, and weight and height measurements were obtained. Dual-energy X-ray Absorptiometry (DXA) was obtained at screening and was repeated if more than a month had passed at the time of the study.

After a 12-h overnight fast (except for water), two fasting blood samples were obtained, and a standard ( $1.75 \mathrm{~g} / \mathrm{kg}$ bodyweight (up to $75 \mathrm{~g}$ )) 3-h, oral glucose tolerance test (OGTT) was performed as described by Yeckel et al. [29]. 
Subsequently, the participants were transferred to the radiology department at Texas Children's Hospital for Magnetic Resonance Imaging and Spectroscopy (MRI/MRS) of abdominal and hepatic fat content, respectively.

\subsection{Body Composition Analyses}

Non-bone lean body mass, fat mass and body fat \% were measured and calculated by DXA (QDR 11.2; Hologic Inc., Bedford, MA, USA) $[8,16,27]$. Abdominal fat content was measured by MRI and intrahepatic fat content by MRS using a Philips Achieva 1.5T whole body scanner, Software Release 1.5, (Best, Holland) [8]. The MR image of abdominal fat, i.e., visceral and subcutaneous fat content, was acquired in a single transversal slice at the level of the umbilicus. MRI data are expressed as cross-sectional area $\left(\mathrm{cm}^{2}\right)$. Hepatic fat content is expressed as the total lipid/water peak area ratio (\%) [8]. Hepatic fat was considered normal if the MRS lipid peak/water peak was $<5.6 \%$ and high if the MRS lipid peak/water peak was $>5.6 \%[8,30]$.

\subsection{Biochemical Analyses}

Plasma concentrations of glucose and insulin were measured to calculate insulin resistance and insulin sensitivity. Adipocyte dysfunction was evaluated by measuring plasma concentrations of leptin and adiponectin. Whole body inflammation was assessed by measuring the plasma concentration of the downstream marker of inflammation, high sensitivity C-reactive protein (Hs-CRP) [14]. All biochemical parameters were measured as previously described [16]. Hs-CRP categorizes cardiovascular disease risk in adults as follows: $\mathrm{Hs}-\mathrm{CRP}<1.0 \mathrm{mg} / \mathrm{L}$ lowest risk; $1.0-3.0 \mathrm{mg} / \mathrm{L}$ average risk; $>3.0 \mathrm{mg} / \mathrm{L}$ highest risk [31].

Insulin resistance was calculated by the Homeostasis model Assessment (HOMA-IR: fasting insulin $\mu \mathrm{U} / \mathrm{mL} \times$ fasting glucose mmol/1 /22.5) [32]. HOMA-IR $>3.29$ was considered insulin resistant [33]. Insulin sensitivity was calculated by the Whole Body Insulin Sensitivity Index (WBISI: $(10,000 / \sqrt{ }(($ fasting glucose $\times$ fasting insulin $) \times($ mean glucose $120 \mathrm{~min} \times$ mean insulin $120 \mathrm{~min})))$ [29,34] . Currently, no WBISI cut-off value exists to define insulin resistance.

\subsection{Statistical Methods}

Data are presented as the mean \pm SD. Pearson correlation was used to test for correlations between variables. Differences between groups were assessed by a two-sided unpaired $t$-test. $p \leq 0.05$ was considered statistically significant.

The subjects' pubertal stage, age and height were similar between the two N-BMI groups. However, weight $(p<0.01)$, BMI $(p<0.01)$, body fat $\%$, $(p<0.01)$ fat mass $(p<0.01)$ subcutaneous fat $(p$ $<0.01)$, visceral fat $(p<0.05)$ and hepatic fat $(p<0.01)$ were all higher in the N-BMI-HF girls.

\subsection{Metabolic Risk Indicators}

Metabolic risk indicators of the N-BMI-HF $(n=15)$, the N-BMI-NF $(n=8)$, as well as that of the whole N-BMI group are presented in Table 2. The N-BMI-HF group had higher plasma insulin $(p \leq 0.05)$, leptin $(p \leq 0.01)$ and Hs-CRP $(p \leq 0.05)$ concentrations and higher HOMA-IR values $(p \leq 0.05)$, when compared to those of the N-BMI-NF adolescents. Moreover, all participants with signs of insulin resistance and a high CRP were in the N-BMI-HF group. Below BMI $22.4 \mathrm{~kg} / \mathrm{m}^{2}$, no insulin resistance was observed. No difference between groups was found in adiponectin concentrations despite the fact that the mean values were lower in the HF group.

\section{Results}

\subsection{Clinical Characteristics}

Demographic and body composition characteristics of the girls with a N-BMI-HF $(n=15)$ and with a N-BMI-NF\% $(n=8)$, as well as that of the whole group of N-BMI participants (results of N-BMI-NF and N-BMI-HF combined; $\mathrm{N}=23$ ) are presented in Table 1. 
Table 1. Clinical characteristics and body composition (mean $\pm \mathrm{SD}$ ).

\begin{tabular}{cccc}
\hline & N-BMI & N-BMI-NF & N-BMI-HF \\
\hline N & 23 & 8 & 15 \\
Pubertal stage (Tanner) & IV-V & IV-V & IV-V \\
Age $(\mathrm{y})$ & $14.3 \pm 1.3$ & $14.0 \pm 1.1$ & $14.5 \pm 1.5$ \\
Height $(\mathrm{m})$ & $1.56 \pm 0.1$ & $1.55 \pm 0.1$ & $1.55 \pm 0.1$ \\
Weight $(\mathrm{kg})$ & $50.9 \pm 7.7$ & $43.2 \pm 4.4$ & $55.1 \pm 5.6^{* *}$ \\
BMI $\left(\mathrm{kg} / \mathrm{m}^{2}\right)$ & $20.8 \pm 2.5$ & $18.0 \pm 0.9$ & $22.3 \pm 1.6^{* *}$ \\
Body fat $\%$ & $29.3 \pm 5.3$ & $23.1 \pm 1.0$ & $32.5 \pm 2.6^{* *}$ \\
Lean body mass $(\mathrm{kg})$ & $34.5 \pm 3.9$ & $32.0 \pm 3.3$ & $35.9 \pm 3.6^{* *}$ \\
Fat mass $(\mathrm{kg})$ & $15.5 \pm 4.8$ & $10.1 \pm 1.6$ & $18.4 \pm 3.0^{* *}$ \\
Subcutaneous fat $\left(\mathrm{cm}^{2}\right)$ & $184 \pm 71$ & $110 \pm 37$ & $224 \pm 9^{* *}$ \\
Visceral fat $\left(\mathrm{cm}^{2}\right)$ & $16 \pm 10$ & $10 \pm 6$ & $18 \pm 10^{*}$ \\
Hepatic fat $(\%)$ & $1.0 \pm 0.7$ & $0.5 \pm 0.2$ & $1.2 \pm 0.8^{* *}$ \\
\hline
\end{tabular}

N-BMI = mean of N-BMI-NF and N-BMI-HF combined; N-BMI-NF = Normal BMI Normal body Fat $\%$; N-BMI-HF = Normal BMI High body Fat \%. Different between N-BMI-NF and N-BMI-HF participants. ${ }^{*} p \leq 0.05^{* *} p \leq 0.01$.

Table 2. Metabolic risk indicators (mean $\pm \mathrm{SD}$ ).

\begin{tabular}{cccc}
\hline & N-BMI & N-BMI-NF & N-BMI-HF \\
\hline N & 23 & 8 & 15 \\
Glucose $(\mathrm{mmol} / \mathrm{L})$ & $4.86 \pm 0.37$ & $4.91 \pm 0.33$ & $4.81 \pm 0.40$ \\
Insulin $(\mu \mathrm{U} / \mathrm{mL})$ & $10.6 \pm 4.8$ & $7.9 \pm 3.0$ & $12.0 \pm 5.0^{*}$ \\
HOMA-IR & $2.29 \pm 1.1$ & $1.73 \pm 0.7$ & $2.59 \pm 1.2^{*}$ \\
WBISI & $4.0 \pm 1.7$ & $4.9 \pm 2.0$ & $3.5 \pm 1.4$ \\
Leptin $(\mathrm{ng} / \mathrm{mL})$ & $20.0 \pm 12.2$ & $8.7 \pm 3.5$ & $27.5 \pm 9.8^{* *}$ \\
Adiponectin $(\mathrm{mg} / \mathrm{mL})$ & $11.6 \pm 6.6$ & $14.4 \pm 9.5$ & $10.1 \pm 4.0$ \\
Hs-CRP $(\mathrm{mg} / \mathrm{L})$ & $0.96 \pm 1.39$ & $0.31 \pm 0.19$ & $1.30 \pm 1.62^{*}$ \\
\hline
\end{tabular}

$\mathrm{N}-\mathrm{BMI}=$ mean of N-BMI-NF and N-BMI-HF combined. Different between N-BMI-NF and N-BMI-HF participants. ${ }^{*} p \leq 0.05^{* *} p \leq 0.01$.

\subsection{Correlations of N-BMI (N-BMI-NF and N-BMI-HF Combined)}

BMI and body fat $\%$ were significantly correlated $(p \leq 0.01)$. Not surprisingly, both BMI and body fat $\%$ correlated with fat mass $(p \leq 0.01)$, subcutaneous fat $(p \leq 0.01)$ and visceral fat $(p \leq 0.01$ and $p \leq 0.05$, respectively). Both BMI and body fat $\%$ correlated with, hepatic fat $(p \leq 0.05)$, fasting insulin $(p \leq 0.05)$, HOMA IR $(p \leq 0.05)$, WBISI $(p \leq 0.05)$ and leptin $(p \leq 0.01)$ (Figure 1$)$.

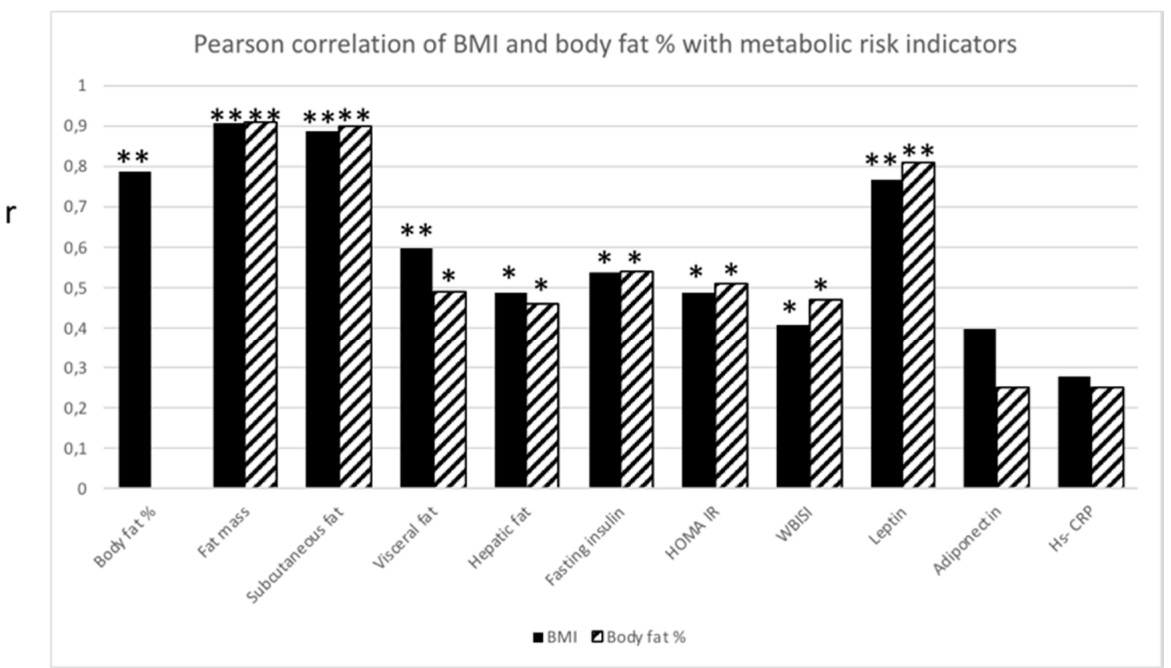

Figure 1. Pearson correlation analysis between BMI (black bar) and body fat \% (striped bar), respectively, and metabolic risk indicators. Significant correlation (r) between BMI or body fat \% with metabolic risk indicators. ${ }^{*} p \leq 0.05 ;{ }^{* *} p \leq 0.01$. 
Both HOMA-IR and WBISI correlated with all measures of abdominal fat distribution $(p \leq 0.05)$ except for visceral fat, which solely correlated with HOMA-IR $(p \leq 0.05)$. In addition, both parameters correlated significantly with leptin $(p \leq 0.01)$, but not with adiponectin or Hs-CRP (Figure 2).

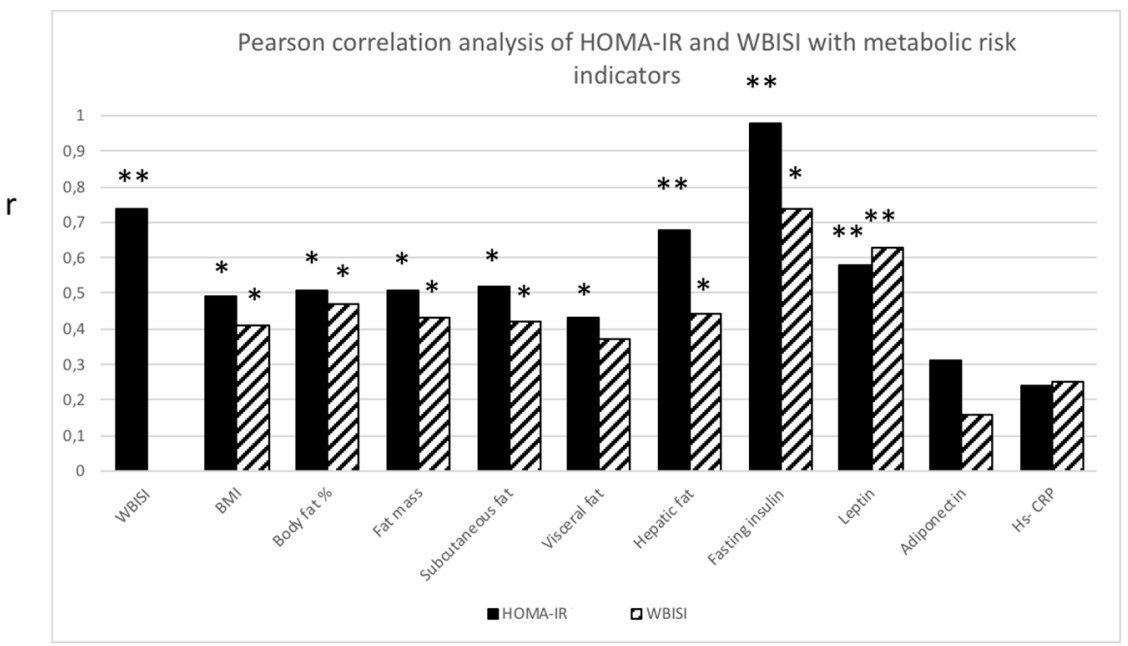

Figure 2. Pearson correlation analysis between homeostasis Model Assessment Insulin Resistance (HOMA-IR; black bar) and Whole Body Insulin Sensitivity Index (WBISI; striped bar) with metabolic risk indicators. Significant correlation (r) between HOMA-IR or WBISI with metabolic risk indicators. ${ }^{*} p \leq 0.05 * * p \leq 0.01$.

\section{Discussion}

This study shows that a normal BMI in sedentary Hispanic adolescent girls is not an indicator of the absence of metabolic risk. In this group of subjects, a high body fat $\%$, also in the presence of a normal BMI, is associated with metabolic risk factors and altered body composition. These girls present increased fat mass, abdominal fat deposits, insulin resistance and increased plasma concentrations of insulin and leptin. Moreover, low grade chronic whole body inflammation, measured by high Hs-CRP, was detected in adolescents with a high body fat $\%$, as previously described in obese adolescents $[15,16]$. Collectively, these data indicate that these girls with a BMI $<85$ th percentile and a high body fat $\%$ have an increased risk of cardiovascular disease $[14,35,36]$ as recently described in a Finish seven-year longitudinal study in children and adolescent girls with normal BMI, but high body fat \% [37].

High adiponectin concentration is purported to have a protective effect on insulin sensitivity partly attributed to its anti-inflammatory function [18] and is lower in obese adolescents [38]. The lack of correlation between insulin resistance measures and adiponectin concentrations in our participants suggest that within the normal BMI range, insulin resistance and low grade whole body inflammation may not be the result of a diminished "protective effect" of this adipokine. Nonetheless, a non-significant progressive decline in adiponectin can be observed in previously studied high BMI adolescent girls ( $>95$ th percentile for age; adiponectin $6.6 \pm 3.0 \mathrm{mg} / \mathrm{mL}$ ) $[8,16,27]$ as compared to N-BMI-HF and N-BMI-NF adolescents, indicating the metabolic role of this adipokine in obesity-related disease. However, since total adiponectin and not the physiologically more active High Molecular Weight (HMW) adiponectin was measured, a potential difference of HMW adiponectin distribution between groups cannot be excluded [39].

Increased abdominal fat, specifically visceral fat [40], is an important contributor to obesity-related risk indicators in obese adolescents $[8,10,11,13,40,41]$ in part by contributing to the chronic state of whole body inflammation [40]. In addition, subcutaneous fat content has also been related to metabolic disorders in pre-pubertal children [41,42]. It has been suggested that the accumulation of subcutaneous fat may be a normal physiological response that prevents storage of fat accumulation in ectopic sites such as liver and muscle to decrease the risk of obesity-related metabolic disturbances $[9,13]$. 
The progressive increase in visceral and hepatic fat, combined with the increased insulin resistance, suggests that the subcutaneous adipose tissue is insufficient to take up fat in our studied sedentary normal BMI Hispanic adolescents (adiposopathy) [12,13]. Although hepatic fat content remained within the normal range in all participants, higher hepatic fat in HF girls warrants attention. No follow-up study could be done in the studied group of subjects to determine if these adolescents with higher hepatic fat actually developed non-alcoholic fatty liver disease $[8,23,43]$.

The results of the present study demonstrate that a normal BMI, as currently defined, is not a good indicator of the absence of metabolic risk in this group of Hispanic adolescent girls. A high body fat $\%$ in these girls is related to increased metabolic risk indicators. Currently, no consensus exists on the definition of normal body fat \% $[5,28]$. Here, we demonstrate that metabolic derangements are present in normal BMI adolescent girls with a body fat $\% \geq 27$, indicating that using the higher body fat $\%$ cut-off criteria published by Flegal et al. [5] (average body fat \% of Mexican American girls of 34.7) results in a dramatic underestimation of metabolic risk. The problem with the current cut-off criteria using BMI or body fat $\%$ is that these criteria solely rely on the distribution within a certain population rather than on the relation between BMI or body fat $\%$ and the presence of actual metabolic alterations, as reconfirmed in obese children [44]. To identify adequately a population at metabolic risk, we need better BMI and body fat distribution cut-off criteria that would involve the ethnicity, race and sex of the individuals. This problem has particularly been recognized in the Asian ethnic groups [19-21] and resulted in the utilization of lower cut-off of BMI to define obesity in the Asian population $[19,20]$. A weakness of the present study is the small sample size. However, it is representative for the large body fat \% database of normal BMI Hispanic, female adolescents developed by Dr. K. J. Ellis (Children's Nutrition Center, Houston, TX, USA) (data not shown). Other potential limitations of the study are the evaluation of sedentary behavior by self-report and the lack of registration of tobacco use, and although the participants received a controlled diet prior to the study, the effects of prior food habits/diet were not completely ruled out.

In conclusion, sedentary, post-pubertal Hispanic, adolescent girls with a normal BMI can show a body fat \%, fat distribution and metabolic profile that puts them at risk for the development of obesity-related morbidity as is known to occur in Hispanics [22-25]. The development of BMI and body fat \% distribution cut-off criteria per sex, age and racial group based on metabolic risk indicators is needed in order to optimize the effectiveness of metabolic risk screening procedures, or a new and more precise measure to determine whole body adiposity needs to be created.

Author Contributions: Conceptualization, G.V.D.H., P.J.J.S., M.H., A.L.S. Methodology, G.V.D.H., P.J.J.S., A.L.S. Validation, G.V.D.H., P.J.J.S., A.L.S. Formal analysis, G.V.D.H., Z.J.W., Z.D.C., P.J.J.S, A.L.S. Investigation, G.V.D.H., A.L.S. Resources, A.L.S. Data curation, G.V.D.H., A.L.S. Writing, original draft Preparation, G.V.D.H., A.L.S. Writing, review and editing, G.V.D.H., Z.J.W., Z.D.C., P.J.J.S., M.H., A.L.S. Visualization, G.V.D.H., A.L.S. Supervision, A.L.S., P.J.J.S. Project administration, A.L.S. Funding acquisition, A.L.S. This work is a publication of the U.S. Department of Agriculture/Agricultural Research Service, Children's Nutrition Research Center, Department of Pediatrics, Baylor College of Medicine, Houston, Texas. The contents of this publication do not necessarily reflect the views or policies of the U.S. Department of Agriculture, nor does mention of trade names, commercial products or organizations imply endorsement from the U.S. government.

Funding: The study was supported by NICHD RO1 HD044609; Baylor General Clinical Research Center Grant MO1-RR-00188-34 and USDA CRIS 6250-51000-046.

Acknowledgments: We would like to thank all research participants for their time and commitment; Luisa Rodriguez, research nurse Shawn Asphall, research coordinator Janette Gonzalez, dietician Ann McMeans, the Metabolic Research Unit staff at the Children's Nutrition Research Center and the General Clinical Research Center staff at Texas Children's Hospital for their invaluable help in conducting these studies. We thank Susan Sharma and Marcia Ekworomadu for excellent technical assistance and Lidia Szczepaniak, Lynn Trautwein and Rajesh Krishnamurthy for advice regarding MRI/MRS analyses.

Conflicts of Interest: The authors declare no conflict of interest. 


\section{References}

1. Juonala, M.; Magnussen, C.G.; Berenson, G.S.; Venn, A.; Burns, T.L.; Sabin, M.A.; Srinivasan, S.R.; Daniels, S.R.; Davis, P.H.; Chen, W.; et al. Childhood adiposity, adult adiposity, and cardiovascular risk factors. N. Engl. J. Med. 2011, 365, 1876-1885. [CrossRef] [PubMed]

2. Kuczmarski, R.J.; Ogden, C.L.; Grummer-Strawn, L.M.; Flegal, K.M.; Guo, S.S.; Wei, R.; Mei, Z.; Curtin, L.R.; Roche, A.F.; Johnson, C.L. CDC growth charts: United States. Adv. Data 2000, 314, 1-27.

3. Ellis, K.J.; Abrams, S.A.; Wong, W.W. Monitoring childhood obesity: assessment of the weight/height index. Am. J. Epidemiol. 1999, 150, 939-946. [CrossRef] [PubMed]

4. Freedman, D.S.; Ogden, C.L.; Berenson, G.S.; Horlick, M. Body mass index and body fatness in childhood. Curr. Opin. Clin. Nutr. Metab. Care 2005, 8, 618-623. [CrossRef] [PubMed]

5. Flegal, K.M.; Ogden, C.L.; Yanovski, J.A.; Freedman, D.S.; Shepherd, J.A.; Graubard, B.I.; Borrud, L.G. High adiposity and high body mass index-for-age in US children and adolescents overall and by race-ethnic group. Am. J. Clin. Nutr. 2010, 91, 1020-1026. [CrossRef] [PubMed]

6. Gutin, B.; Yin, Z.; Humphries, M.C.; Hoffman, W.H.; Gower, B.; Barbeau, P. Relations of fatness and fitness to fasting insulin in black and white adolescents. J. Pediatr. 2004, 145, 737-743. [CrossRef] [PubMed]

7. Lamb, M.M.; Ogden, C.L.; Carroll, M.D.; Lacher, D.A.; Flegal, K.M. Association of body fat percentage with lipid concentrations in children and adolescents: United States, 1999-2004. Am. J. Clin. Nutr. 2011, 94, 877-883. [CrossRef] [PubMed]

8. Van der Heijden, G.-J.; Wang, Z.J.; Chu, Z.D.; Sauer, P.J.J.; Haymond, M.W.; Rodriguez, L.M.; Sunehag, A.L. A 12-week aerobic exercise program reduces hepatic fat accumulation and insulin resistance in obese, Hispanic adolescents. Obesity 2010, 18, 384-390. [CrossRef] [PubMed]

9. Taksali, S.E.; Caprio, S.; Dziura, J.; Dufour, S.; Calí, A.M.; Goodman, T.R.; Papademetris, X.; Burgert, T.S.; Pierpont, B.M.; Savoye, M.; et al. High visceral and low abdominal subcutaneous fat stores in the obese adolescent: A determinant of an adverse metabolic phenotype. Diabetes 2008, 57, 367-371. [CrossRef] [PubMed]

10. Caprio, S.O.; Hyman, L.D.; Limb, C.H.; McCarthy, S.H.; Lange, R.O.; Sherwin, R.S.; Shulman, G.E.; Tamborlane, W.V. Central adiposity and its metabolic correlates in obese adolescent girls. Am. J. Physiol. Endocrinol. Metab. 1995, 269, E118-E126. [CrossRef] [PubMed]

11. Liska, D.; Dufour, S.; Zern, T.L.; Taksali, S.; Calí, A.M.; Dziura, J.; Shulman, G.I.; Pierpont, B.M.; Caprio, S. Interethnic differences in muscle, liver and abdominal fat partitioning in obese adolescents. PLOS ONE 2007, 2. [CrossRef] [PubMed]

12. Bays, H.E. Adiposopathy: Is "sick fat" a cardiovascular disease? J. Am. Coll Cardiol. 2011, 57, $2461-2473$. [CrossRef] [PubMed]

13. Caprio, S.; Perry, R.; Kursawe, R. Adolescent Obesity and Insulin Resistance: Roles of Ectopic Fat Accumulation and Adipose Inflammation. Gastroenterology 2017, 152, 1638-1646. [CrossRef] [PubMed]

14. Balagopal, P.B.; de Ferranti, S.D.; Cook, S.; Daniels, S.R.; Gidding, S.S.; Hayman, L.L.; McCrindle, B.W.; Mietus-Snyder, M.L.; Steinberger, J. Nontraditional risk factors and biomarkers for cardiovascular disease: mechanistic, research, and clinical considerations for youth: a scientific statement from the American Heart Association. Circulation 2011, 123, 2749-2769. [CrossRef] [PubMed]

15. De Luca, C.; Olefsky, J.M. Inflammation and insulin resistance. FEBS Lett. 2008, 582, 97-105. [CrossRef] [PubMed]

16. Van Der Heijden, G.J.; Toffolo, G.; Manesso, E.; Sauer, P.J.J.; Sunehag, A.L. Aerobic exercise increases peripheral and hepatic insulin sensitivity in sedentary adolescents. J. Clin. Endocrinol. Metab. 2009, 94, 4292-4299. [CrossRef] [PubMed]

17. Wallace, A.M.; McMahon, A.D.; Packard, C.J.; Kelly, A.; Shepherd, J.; Gaw, A.; Sattar, N. Plasma leptin and the risk of cardiovascular disease in the west of Scotland coronary prevention study (WOSCOPS). Circulation 2001, 104, 3052-3056. [CrossRef] [PubMed]

18. Jeffery, A.N.; Murphy, M.J.; Metcalf, B.S.; Hosking, J.; Voss, L.D.; English, P.; Sattar, N.; Wilkin, T.J. Adiponectin in childhood. Int. J. Pediatr. Obes. 2008, 3, 130-140. [CrossRef] [PubMed]

19. WHO Expert Consultation. Appropriate body-mass index for Asian populations and its implications for policy and intervention strategies. Lancet 2004, 363, 157-163. 
20. Misra, A. Ethnic-Specific Criteria for Classification of Body Mass Index: A Perspective for Asian Indians and American Diabetes Association Position Statement. Diabetes Technol. Ther. 2015, 17, 667-671. [CrossRef] [PubMed]

21. Hudda, M.T.; Nightingale, C.M.; Donin, A.S.; Fewtrell, M.S.; Haroun, D.; Lum, S.; Williams, J.E.; Owen, C.G.; Rudnicka, A.R.; Wells, J.C.; et al. Body mass index adjustments to increase the validity of body fatness assessment in UK Black African and South Asian children. Int. J. Obes. 2017, 41, 1048-1055. [CrossRef] [PubMed]

22. Ogden, C.L.; Carroll, M.D.; Kit, B.K.; Flegal, K.M. Prevalence of childhood and adult obesity in the United States, 2011-2012. JAMA 2014, 311, 806-814. [CrossRef] [PubMed]

23. Schwimmer, J.B.; Deutsch, R.; Kahen, T.; Lavine, J.E.; Stanley, C.; Behling, C. Prevalence of fatty liver in children and adolescents. Pediatrics 2006, 118, 1388-1393. [CrossRef] [PubMed]

24. Narayan, K.M.V.; Boyle, J.P.; Thompson, T.J.; Sorensen, S.W.; Williamson, D.F. Lifetime risk for diabetes mellitus in the United States. JAMA 2003, 290, 1884-1890. [CrossRef] [PubMed]

25. Heiss, G.; Snyder, M.L.; Teng, Y.; Schneiderman, N.; Llabre, M.M.; Cowie, C.; Carnethon, M.; Kaplan, R.; Giachello, A.; Gallo, L.; et al. Prevalence of metabolic syndrome among hispanics/latinos of diverse background: The Hispanic Community Health Study/Study of Latinos. Diabetes Care 2014, 37, 2391-2399. [CrossRef] [PubMed]

26. Ellis, K.J.; Abrams, S.A.; Wong, W.W. Body composition of a young, multiethnic female population. Am. J. Clin. Nutr. 1997, 65, 724-731. [CrossRef] [PubMed]

27. Van Der Heijden, G.J.; Wang, Z.J.; Chu, Z.; Toffolo, G.; Manesso, E.; Sauer, P.J.J.; Sunehag, A.L. Strength exercise improves muscle mass and hepatic insulin sensitivity in obese youth. Med. Sci. Sports Exerc. 2010, 42, 1973-1980. [CrossRef] [PubMed]

28. Shypailo, R.J.; Butte, N.F.; Ellis, K.J. DXA: Can it be used as a criterion reference for body fat measurements in children? Obesity 2008, 16, 457-462. [CrossRef] [PubMed]

29. Yeckel, C.W.; Weiss, R.; Dziura, J.; Taksali, S.E.; Dufour, S.; Burgert, T.S.; Tamborlane, W.V.; Caprio, S. Validation of insulin sensitivity indices from oral glucose tolerance test parameters in obese children and adolescents. J. Clin. Endocrinol. Metab. 2004, 89, 1096-1101. [CrossRef] [PubMed]

30. Szczepaniak, L.S.; Nurenberg, P.; Leonard, D.; Browning, J.D.; Reingold, J.S.; Grundy, S.; Hobbs, H.H.; Dobbins, R.L. Magnetic resonance spectroscopy to measure hepatic triglyceride content: Prevalence of hepatic steatosis in the general population. Am. J. Physiol. Endocrinol. Metab. 2005, 288, E462-E468. [CrossRef] [PubMed]

31. Pearson, T.A.; Mensah, G.A.; Alexander, R.W.; Anderson, J.L.; Cannon, R.O.; Criqui, M.; Fadl, Y.Y.; Fortmann, S.P.; Hong, Y.; Myers, G.L.; et al. Markers of inflammation and cardiovascular disease: Application to clinical and public health practice: A statement for healthcare professionals from the centers for disease control and prevention and the American Heart Association. Circulation 2003, 107, 499-511. [CrossRef] [PubMed]

32. Matthews, D.R.; Hosker, J.P.; Rudenski, A.S.; Naylor, B.A.; Treacher, D.F.; Turner, R.C. Homeostasis model assessment insulin resistance and beta-cell function from fasting plasma glucose and insulin concentrations in man. Diabetologia 1985, 28, 412-419. [CrossRef] [PubMed]

33. Lee, J.M.; Okumura, M.J.; Davis, M.M.; Herman, W.H.; Gurney, J.G. Prevalence and determinants of insulin resistance among U.S. adolescents: A population-based study. Diabetes Care 2006, 29, 2427-2432. [CrossRef] [PubMed]

34. Matsuda, M.; DeFronzo, R.A. Insulin sensitivity indices obtained from oral glucose tolerance testing: Comparison with the euglycemic insulin clamp. Diabetes Care 1999, 22, 1462-1470. [CrossRef] [PubMed]

35. Weiss, R.; Dziura, J.; Burgert, T.S.; Tamborlane, W.V.; Taksali, S.E.; Yeckel, C.W.; Allen, K.; Lopes, M.; Savoye, M.; Morrison, J.; et al. Obesity and the metabolic syndrome in children and adolescents. N. Engl. J. Med. 2004, 350, 2362-2374. [CrossRef] [PubMed]

36. Ferrannini, E.; Balkau, B.; Coppack, S.W.; Dekker, J.M.; Mari, A.; Nolan, J.; Walker, M.; Natali, A.; Beck-Nielsen, H. Insulin resistance, insulin response, and obesity as indicators of metabolic risk. J. Clin. Endocrinol. Metab. 2007, 92, 2885-2892. [CrossRef] [PubMed]

37. Wiklund, P.; Törmäkangas, T.; Shi, Y.; Wu, N.; Vainionpää, A.; Alen, M.; Cheng, S. Normal-weight obesity and cardiometabolic risk: A 7-year longitudinal study in girls from prepuberty to early adulthood. Obesity 2017, 25, 1077-1082. [CrossRef] [PubMed] 
38. Sunehag, A.L.; Toffolo, G.; Campioni, M.; Bier, D.M.; Haymond, M.W. Effects of Dietary Macronutrient Intake on Insulin Sensitivity and Secretion and Glucose and Lipid Metabolism in Healthy, Obese Adolescents. J. Clin. Endocrinol. Metab. 2005, 90, 4496-4502. [CrossRef] [PubMed]

39. Van Andel, M.; Heijboer, A.C.; Drent, M.L. Adiponectin and Its Isoforms in Pathophysiology. In Advances in Clinical Chemistry; Elsevier: New York, NY, USA, 2018; pp. 115-147.

40. Mathieu, P.; Poirier, P.; Pibarot, P.; Lemieux, I.; Després, J.P. Visceral obesity the link among inflammation, hypertension, and cardiovascular disease. Hypertension 2009, 53, 577-584. [CrossRef] [PubMed]

41. Gower, B.A.; Nagy, T.R.; Goran, M.I. Visceral fat, insulin sensitivity, and lipids in prepubertal children. Diabetes 1999, 48, 1515-1521. [CrossRef] [PubMed]

42. Maffeis, C.; Manfredi, R.; Trombetta, M.; Sordelli, S.; Storti, M.; Benuzzi, T.; Bonadonna, R.C. Insulin sensitivity is correlated with subcutaneous but not visceral body fat in overweight and obese prepubertal children. J. Clin. Endocrinol. Metab. 2008, 93, 2122-2128. [CrossRef] [PubMed]

43. Burgert, T.S.; Taksali, S.E.; Dziura, J.; Goodman, T.R.; Yeckel, C.W.; Papademetris, X.; Constable, R.T.; Weiss, R.; Tamborlane, W.V.; Savoye, M.; et al. Alanine aminotransferase levels and fatty liver in childhood obesity: Associations with insulin resistance, adiponectin, and visceral fat. J. Clin. Endocrinol. Metab. 2006, 91, 4287-4294. [CrossRef] [PubMed]

44. Morandi, A.; Miraglia Del Giudice, E.; Martino, F.; Martino, E.; Bozzola, M.; Maffeis, C. Anthropometric indices are not satisfactory predictors of metabolic comorbidities in obese children and adolescents. J. Pediatr. 2014, 165, 1178-1183. [CrossRef] [PubMed]

(C) 2018 by the authors. Licensee MDPI, Basel, Switzerland. This article is an open access article distributed under the terms and conditions of the Creative Commons Attribution (CC BY) license (http://creativecommons.org/licenses/by/4.0/). 